\title{
Correction: Generation and characterization of a novel hematopoietic progenitor cell line with DC differentiation potential
}

\author{
C. Rathinam - M. Sauer - A. Ghosh $\cdot$ C. Rudolph - A. Hegazy - B. Schlegelberger · K. Welte $\cdot$ C. Klein
}

Published online: 27 January 2021

(c) The Author(s), under exclusive licence to Springer Nature Limited 2021

Correction to: Leukemia

https://doi.org/10.1038/sj.leu.2404157

Following the publication of this article it was brought to the attention of the authors that several aspects on FACS staining methodology were not clearly described.

The authors make the following clarifications to the affected figures below:

In Fig. 2, spleen and bone marrow cells were mixed and stained with PE-conjugated isotype antibodies.

In Fig. 4, negative control stains for cell surface expression of CD40/CD86 refer to mononuclear cells stained with a rat IgG2a isotype control antibody.

The conclusions of the article were not affected. The authors apologize for any inconvenience caused. 